\title{
Nafion-mesoporous silica composite electrolyte: properties and direct ethanol fuel cells performance
}

\author{
Z. Ahmed ${ }^{1}$ - B. R. Matos $^{2}$ - D. Z. de Florio ${ }^{3}$ J. F. Q. Rey ${ }^{3}$ E. I. Santiago ${ }^{2}$ • \\ F. C. Fonseca ${ }^{2}$
}

Received: 6 January 2016/Accepted: 5 March 2016/Published online: 21 March 2016

(c) The Author(s) 2016. This article is published with open access at Springerlink.com

\begin{abstract}
Nafion-mesoporous silica composites were investigated aiming at improved performance of direct ethanol fuel cells (DEFC) operating at high temperature. Mesoporous silica (MPS) was synthesized by a sol-gel technique and added as the inorganic filler into Nafion membranes by casting process. The performance of DEFC using both Nafion and Nafion-MPS composites were evaluated by polarization curves and correlated to the electrical and structural properties of the electrolytes in ethanol environment inferred by impedance spectroscopy and small angle X-ray scattering, respectively. The main results show that Nafion-MPS composite electrolytes exhibit improved performance that was related to a structural pining of the ionic clusters of ethanol-saturated Nafion by the inorganic particles, which resulted in higher proton conductivity of the composite. The experimental results evidenced the relevance of a better understanding of the properties of Nafion-based electrolytes to further develop the direct alcohol fuel cells technology.
\end{abstract}

Keywords Mesoporous silica - Direct ethanol fuel cells · Nafion · Proton conductivity

\section{Z. Ahmed}

ZAKARYA_AHMED78@YAHOO.FR

1 National Center for Research and Materials Science (CNRSM), Cedria Science and Technology Park, Route Touristique Borj Cédria, B.P 174, 1164 Hammam-Chatt, Tunisia

2 Instituto de Pesquisas Energéticas e Nucleares, São Paulo, SP 05508-000, Brazil

3 Universidade Federal do ABC, Santo André, SP 09090-400, Brazil

\section{Introduction}

The proton exchange membrane fuel cell (PEMFC) has emerged as a promising electrical energy supply for portable, vehicular, and stationary applications. It is known that high PEMFC performance is achieved when fed with pure hydrogen fuel. However, due to problems associated with hydrogen production, handling, storage, and distribution, it becomes necessary the search for alternative fuels. In this context, liquid fuels, such as methanol and ethanol, have been explored as possible candidates. Such alcohol fuels can be directly fed in PEMFC and the power density is provided by the direct alcohol oxidation, being so-called Direct Alcohol Fuel Cell (DAFC) [1]. Proton exchange membrane (PEM) fuel cells that use either hydrogen or alcohol as fuels are promising power sources for transportation and portable power [1]. Compared to hydrogen fed fuel cells, direct alcohol fuel cells (DAFC) have the advantage of easier system design and operation [1].

Methanol fuelled DAFCs are the main focus of intense research due to the large scale of methanol production and easy handling. However, compared to methanol, ethanol has been praised as a promising fuel for DAFC due to its lower toxicity and renewability $[1,2]$. Nevertheless, DEFC (direct ethanol fuel cell) has some drawbacks, such as low power capacity at low temperature, and high permeability of ethanol by Nafion electrolyte, which provides a substantial crossover of the fuel from the anode to the cathode [3]. In spite of the complete oxidation of one ethanol molecule to involve 12 electrons, such a reaction is limited to 4 electrons in low temperature fuel cell promoting basically the formation of acetaldehyde and acetic acid. Such limitation is caused by an incomplete ethanol oxidation due to difficulty of 
$\mathrm{C}-\mathrm{C}$ bond cleavage of the ethanol molecule [4]. On the other hand, the crossover effect promotes the adsorption of the fuel and their intermediates onto cathode, diminishing the oxygen reduction reaction (ORR) rate and, consequently, the overall performance of the fuel cell [3, 4]. The poor kinetics of alcohol electro-oxidation and crossover through the polymer electrolyte are important drawbacks that hinder the boost of performance of DAFCs [3, 4]. To develop the direct ethanol fuel cell (DEFC) technology a great deal of attention has been given to the development of electrocatalysts able to oxidize ethanol, but relatively less effort has been devoted to improve the performance of the electrolytes with increased conductivity at high temperature and lower fuel crossover [5].

Perfluorosulfonate membranes, such as Nafion, are the most used electrolyte due to their good proton conductivity and chemical stability. However, limitations associated with both limited temperature range of operation and alcohol permeability (fuel crossover) have triggered an extensive research to improve the high temperature properties of Nafion membranes [3,5]. Previous works were carried out to reduce fuel crossover and to improve Nafionbased membranes performance by incorporating oxide particles, such as $\mathrm{SiO}_{2}, \mathrm{TiO}_{2}$, and $\mathrm{H}_{2} \mathrm{Ti}_{3} \mathrm{O}_{7} \cdot \mathrm{H}_{2} \mathrm{O}$ (titanate nanotubes), obtaining promising results [6-9]. Such an improved performance has been attributed to the hygroscopic properties of the oxide phase, which allow the fuel cell operation at higher temperature and, consequently, favor the fuel oxidation kinetics [6, 7]. Among different oxide phases, composites with silica particles in the composition have demonstrated superior performance in PEMFC operating at high temperature. Such a feature has been explained in terms of improved water retention into conductive channels of the Nafion due to the higher water sorption properties of silica. In addition, the morphology of the oxide phase seems to be an important parameter in the hygroscopic properties of the composites. In this context, mesoporous silica-based composite with high proton conductivity, as a result of the ordered structure of pores, was described as an alternative electrolyte for fuel cell applications [10].

The main goal of the present study is to combine the transport properties of mesoporous and hygroscopic silicon oxide to prepare Nafion-based electrolytes for DEFCs operating at high temperature. Composite membranes based on Nafion ionomer containing mesoporous silica (MPS) were fabricated by casting and characterized aiming at a reduced fuel crossover and enhanced performance at high temperature. The effects of the MPS filler on both the polymer morphology and proton transport properties were investigated.

\section{Experimental}

\section{Mesoporous silica synthesis}

Mesoporous silica (MPS) was prepared using tetraethyl orthosilicate (TEOS) and triblock copolymers as a surfactant (Pluronic F127, BASF). Pluronic F127 (1 g) was dissolved in $40 \mathrm{~mL}$ of $0.5 \mathrm{M} \mathrm{HCl}$ at room temperature, then TEOS $(4 \mathrm{~g})$ was added drop wise at $40{ }^{\circ} \mathrm{C}$. The resulting slurry was stirred at $40{ }^{\circ} \mathrm{C}$ for $6 \mathrm{~h}$. The product was aged overnight at $100{ }^{\circ} \mathrm{C}$ and the resulting solution was filtered. To remove the surfactant, the obtained powders were calcined at $600{ }^{\circ} \mathrm{C}$ (heating rate of $2{ }^{\circ} \mathrm{C} / \mathrm{min}$ ) for $7 \mathrm{~h}$.

\section{Membrane preparation}

Nafion solution [5 \% (w/w), DuPont] was firstly evaporated at $80{ }^{\circ} \mathrm{C}$ and re-dissolved in $10 \mathrm{~mL}$ of dimethyl sulfoxide (DMSO). A dispersion of MPS in DMSO was prepared separately and then added to the Nafion solution ( $5 \mathrm{wt} \%$ of MPS). The mixture was kept under stirring for $24 \mathrm{~h}$, dropped in a Teflon mold, and dried in oven at $150{ }^{\circ} \mathrm{C}$ for $4 \mathrm{~h}$. The obtained film was then post-treated in $7 \mathrm{~mol} / \mathrm{L} \mathrm{HNO}_{3}, 3 \%$ (w/w) $\mathrm{H}_{2} \mathrm{O}_{2}$ and $0.5 \mathrm{M} \mathrm{H}_{2} \mathrm{SO}_{4}$, to clean the membrane. Final thicknesses of membranes were $\sim 110 \mu \mathrm{m}$. Recast Nafion membranes were prepared by following the same procedure.

\section{Physico-chemical characterization}

Nafion-MPS composite membranes were characterized by small-angle X-ray scattering (SAXS) at ambient humidity to study the effect of the filler on the Nafion morphology. To understand the effect of ethanol on the structure of Nafion, SAXS measurements were also performed on membranes swollen in ethanol solution (2 M). SAXS experiments were carried out using Bruker Nanostar. Experiments were conducted with an incident wavelength $\lambda=1.5418 \AA$ in the range of the scattering vector $q \sim 0.006-0.58 / \AA$ ( $q=4 \pi \sin \theta / \lambda$, being $2 \theta$ the scattering angle). Nitrogen adsorption-desorption experiments were conducted on a BELSORP-mini isotherm. The specific surface area of silica particle was determined from Brunauer, Emmett and Teller (BET) equation. Morphology of silica powder was carried out using transmission electron microscopy (TEM, JEOL 2210).

Conductivity measurements were carried out on membranes with $8 \mathrm{~mm}$ diameter, sandwiched between gas diffusion layers, which were pressed on the membrane surfaces by two porous stainless steel discs inside a homemade sample chamber $[11,12]$ that controls both the temperature and the relative humidity. The electrical 
conductivity of membranes was determined as a function of temperature (from 80 to $130^{\circ} \mathrm{C}$ ) by impedance spectroscopy in the frequency range $10 \mathrm{~Hz}$ to $1 \mathrm{MHz}$ with signal amplitude of $100 \mathrm{mV}$. Impedance measurements were carried out in both water and a $2 \mathrm{M}$ solution of water and ethanol.

Electrodes Preparation and DEFC measurementsAnode and cathode were prepared in house, using Pt and Nafion loadings of $1 \mathrm{mg} / \mathrm{cm}^{2}$ and $30 \mathrm{wt} \%$, respectively. PtSn (3:1)/C (20\%, BASF) and Pt/C (20\%, BASF) were used as catalyst for the anode and cathode, respectively.

Composite and Nafion recast membranes were evaluated in a $5 \mathrm{~cm}^{2}$ single fuel cells fed with ethanol solution $(2 \mathrm{~mol} / \mathrm{L}$ ) at flow rates of $4 \mathrm{~mL} / \mathrm{min}$ in the anode, and pure oxygen in the cathode. Measurements were conducted by setting the temperature of fuel cell and oxygen humidifier at 80 or $130{ }^{\circ} \mathrm{C}$, respectively. The anode was kept at room temperature and atmospheric pressure $(1 \mathrm{~atm})$ and the absolute oxygen pressure was set at $3 \mathrm{~atm}$. The polarization data were collected after conditioning of the system in hydrogen anodic feed at $0.7 \mathrm{~V}$ for two hours temperature to assure steady state.

\section{Results and discussion}

$\mathrm{N}_{2}$ adsorption-desorption isotherms of the MPS (Fig. 1) exhibit features of isotherms of type IV, typically observed for ordered mesoporous materials [13]. BET surface area of the silica samples after calcination at $600{ }^{\circ} \mathrm{C}$ is $\sim 428 \mathrm{~m}^{2} /$ g. Figure $1 \mathrm{~b}$ shows a representative TEM image of the mesoporous silica. In the image, the white spots represent the pores and the black contour represents the skeleton of silica matrices. The Fourier Transform (FFT) analysis of the TEM image (Fig. 1c) confirms the presence of ordered porosity in an array of high uniformity with correlation distances of $\sim 5$ and $\sim 9 \mathrm{~nm}$. The large surface specific area and the presence of nanopores in as a hydrophilic network in silica particles resemble Nafion nanophaseseparated morphology.

\section{SAXS measurements (Fig. 2)}

To understand how the fuel may affect cluster structure organization of Nafion, SAXS analyses were performed for dry Nafion and Nafion-MPS composites preconditioned in both ambient relative humidity and saturated with ethanol solution (2 M) as shown in Fig. 4. The SAXS patterns of Nafion preconditioned both in water and in ethanol solution revealed the presence of two characteristics peaks of Nafion, namely, the ionomer peak $(q \sim 0.2 / \AA)$ and the matrix peak $(q \sim 0.05 / \AA)$ [14]. The matrix peak is attributed to the long range correlations among
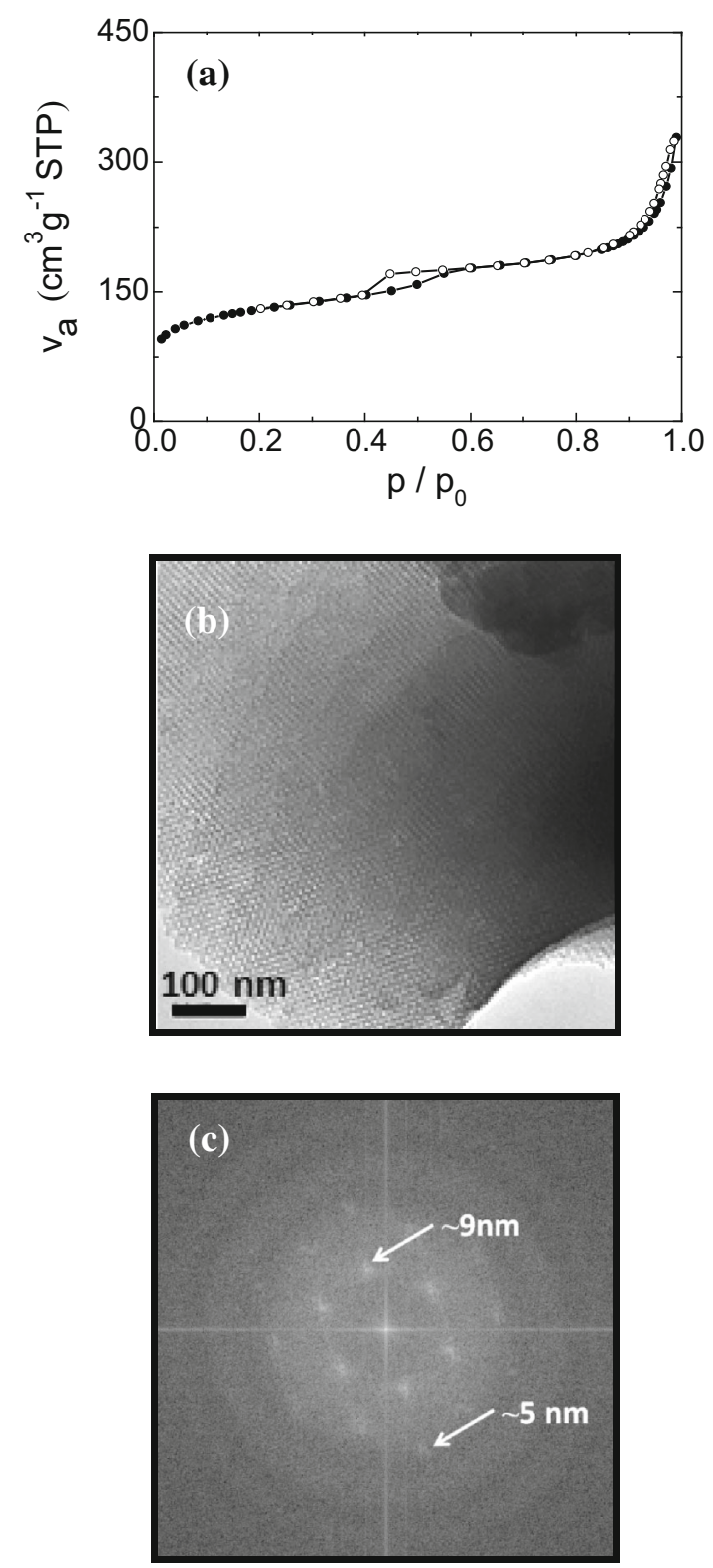

Fig. $1 \mathrm{~N}_{2}$ adsorption-desorption isotherms (a); TEM micrograph (b); and the FFT of the TEM image of mesoporous silica

tetrafluorethylene crystallites and the ionomer peak is assigned to the correlation length among elongated polymeric aggregates [14]. The Bragg spacing $\left(d_{\max }\right)$ due to the ionomer peak is reported to be increased as the water content or alcohol content increases [14, 15]. For membranes at ambient relative humidity, $d_{\max }$ for Nafion and the Nafion-MPS composite is similar $\sim 31$ and $\sim 29 \AA$, respectively. For samples previously swollen in ethanol solutions, $d_{\max }$ of both samples increase to $\sim 34 \AA$ for Nafion and $\sim 31 \AA$

for the composite sample indicating that the microstructure of the Nafion-MPS samples are less sensitive to the presence of ethanol. MPS contributes on 


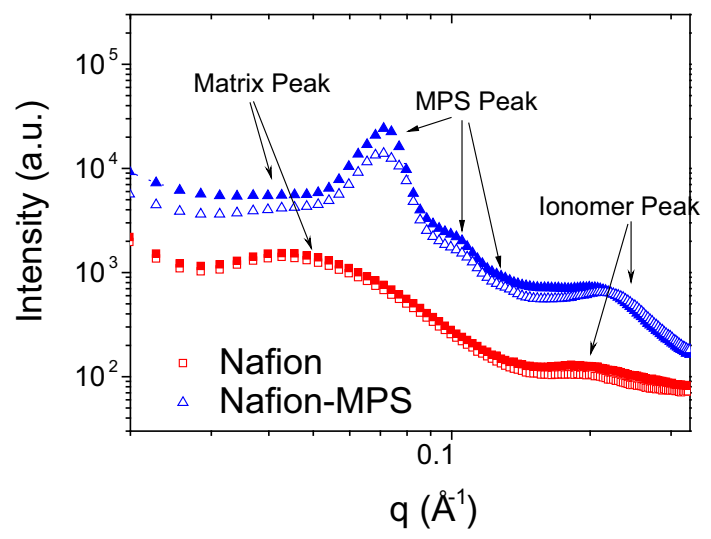

Fig. 2 Small-angle X-ray scattering of Nafion-MPS (closed triangle, open triangle) and Nafion (closed square, open square) membranes at ambient humidity (open symbol) and ethanol swollen state (close symbol)

decreasing the ethanol access to polymer cluster, and as the conductivity of water/ethanol solution decreases with increasing the ethanol volume fraction, a higher conductivity for Nafion-MPS in ethanol solution is expected. It has been recently shown that the addition of titania to Nafion reduces considerably the ethanol uptake [8]. The compactness of Nafion composites is a desirable property for reducing the ethanol permeability during the DEFC operation [8].

The SAXS patterns of Nafion-MPS display two additional scattering intensity upturns at $q$ lower than the ionomer peak that can be attributed to interference scattering due to the correlation length existing in the ordered array of silica mesopores [16]. The shoulder observed at $q \sim 0.1 / \AA$ and the peak at $q \sim 0.07 / \AA$ indicates the presence of a correlation distance among the pores ranging from $\sim 6$ to $\sim 9 \mathrm{~nm}$, which is in good agreement with the correlation distances estimated with the FFT analysis (Fig. 1c). The inorganic arrangement of nanopores can improve the water retention capacity and membrane conductivity at high temperatures of Nafion based composites [10].

\section{Conductivity (Fig. 3)}

To evaluate the effect of filler and ethanol on the Nafion proton conductivity, electrochemical impedance spectroscopy (EIS) measurements under water and ethanol solution vapor were carried out (Fig. 3). The change of the water solvent to the ethanol solution decreases pronouncedly the proton conductivity from $\sigma \sim 0.15$ to $\sigma \sim 0.06 \mathrm{~S} / \mathrm{cm}$ at $80{ }^{\circ} \mathrm{C}$. The increased volume fraction of the solvent with lower proton conductivity (ethanol) can be the main factor associated with the reduction of the Nafion conductivity (Fig. 2). Using the water as solvent, Nafion

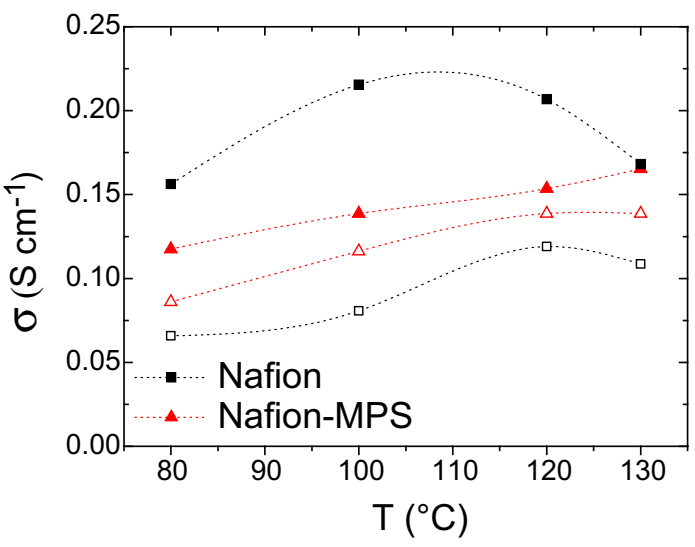

Fig. 3 Temperature dependence of the electrical conductivity of Nafion-MPS (closed triangle, open triangle) and Nafion (closed square, open square) membranes under water vapor (close symbol) and ethanol solution vapor (open symbol)

exhibits superior proton conductivity than the Nafion-MPS composite $(\sigma \sim 0.21 \mathrm{~S} / \mathrm{cm}$ for Nafion and $\sigma \sim 0.14 \mathrm{~S} / \mathrm{cm}$ for Nafion-MPS at $100{ }^{\circ} \mathrm{C}$ ) in the temperature range of $80-130{ }^{\circ} \mathrm{C}$. Similar EIS measurements were carried out under exposure to ethanol solution vapor and it is observed that the ionic conductivities of both polymer and composite samples decrease. However, in ethanol solution, the composite shows higher proton conductivity values than Nafion $(0.12 \mathrm{~S} / \mathrm{cm}$ for the composite and $0.08 \mathrm{~S} / \mathrm{cm}$ for Nafion at $100{ }^{\circ} \mathrm{C}$ ) in all temperature range. One possible explanation for the observed difference is that the proton conduction can be facilitated along the hydrophilic conduction pathways in the silica network [5].

\section{Fuel cell performance (Fig. 4)}

Polarization curves and respective power density curves for DEFCs with membranes electrodes assemblies containing Nafion recast and Nafion-MPS composite membranes were measured at $80{ }^{\circ} \mathrm{C}$ (Fig. 4a) and $130{ }^{\circ} \mathrm{C}$ (Fig. 4b).

The polarization curves obtained at $\sim 80$ and at $130{ }^{\circ} \mathrm{C}$ evidenced typical features of DEFC: (a) a large drop of the open circuit voltage (OCV) with respect to the theoretical equilibrium potential for ethanol electro-oxidation $\left(V_{\text {eq }} \sim 1.145 \mathrm{~V} / T=25^{\circ} \mathrm{C}\right)$ and (b) a large polarization loss at low current densities due to activation polarization $[6,8]$. The OCV drop is usually attributed to the crossover of ethanol molecules from the anode to the cathode whereas the activation polarization is attributed to the sluggish ethanol oxidation reaction [5].

Both Nafion and Nafion-MPS exhibited the typical DEFC profile. However, in terms of performance, at $80{ }^{\circ} \mathrm{C}$ (Fig. 4a) Nafion-MPS is superior to the unmodified Nafion membrane, as observed by the power density values of $\sim 35$ and $26 \mathrm{~mW} / \mathrm{cm}^{2}$, respectively. At $130{ }^{\circ} \mathrm{C}$ the 

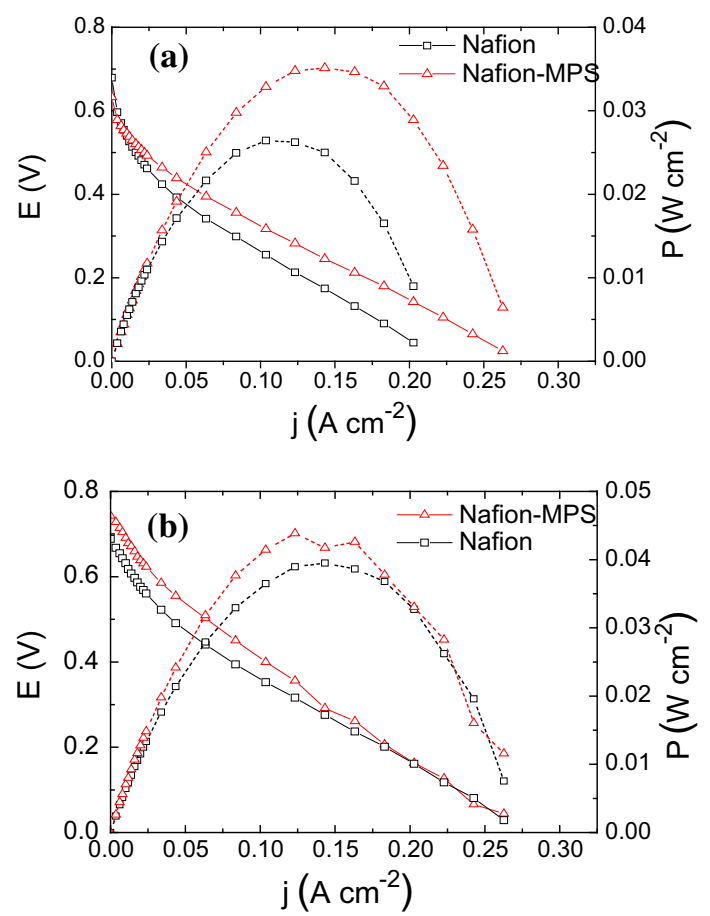

Fig. 4 Polarization (solid line) and power density (dashed line) curves for DEFC operating at $80{ }^{\circ} \mathrm{C}$ (a) and $130{ }^{\circ} \mathrm{C}$ (b) for Nafion (closed square, open square) and Nafion-MPS (closed triangle, open triangle). Anode fed with ethanol flow $4 \mathrm{~mL} / \mathrm{min}$

Nafion-MPS performance is slightly superior $(\sim 44 \mathrm{~mW} /$ $\left.\mathrm{cm}^{2}\right)$ than the one observed for Nafion $\left(\sim 39 \mathrm{~mW} / \mathrm{cm}^{2}\right)$. The higher performance at $80{ }^{\circ} \mathrm{C}$ can be mainly associated with a reduction of the specific resistance of the NafionMPS electrolyte, as can be observed by the lower slope of the linear portion of the polarization curve. This feature is consistent with the conductivity measurements (Fig. 3).On the other hand, the higher performance observed for Nafion-MPS at $130{ }^{\circ} \mathrm{C}$ can be a result of the lower ethanol crossover through the electrolyte, as inferred from the $\mathrm{OCV}$ values.

It is clear that a positive effect on cell performance is given by the addition of mesoporous silica to the Nafion membrane. As previously discussed, presence of hydrophilic nanopores inside Nafion matrix can improve the proton conductivity as well as provide physical barriers hindering the ethanol crossover.

\section{Conclusion}

We prepared composite Nafion membranes filled with mesoporous silica (MPS), and studied the effect of MPS addition on fuel cells test, the proton conductivity and the polymer morphology. SAXS analysis confirm that the presence of MPS particles diminish the effect of ethanol on cluster morphology of Nafion. The addition of MPS increased the direct ethanol fuel cells performances. Moreover, these MPS composites displayed higher proton conductivity relative to pure Nafion under ethanol atmosphere.

Acknowledgments The authors thank the financial support of UFABC, CNPq (502255/2009-9, 577402/2008-0, 402613/2007-4), FAPESP (08/52084-5 and 13/50151-5), CNEN, and FINEP.

Open Access This article is distributed under the terms of the Creative Commons Attribution 4.0 International License (http:// creativecommons.org/licenses/by/4.0/), which permits unrestricted use, distribution, and reproduction in any medium, provided you give appropriate credit to the original author(s) and the source, provide a link to the Creative Commons license, and indicate if changes were made.

\section{References}

1. Song, S., Tsiakaras, P.: App. Catal. B. Environ. 63, 187 (2006)

2. Li, Y.S., Zhao, T.S., Liang, Z.X.: J. Power Sources 187, 387 (2009)

3. Deluca, N.W., Elabd, Y.A.: J. Polym. Sci., Part B: Polym. Phys. 44, 2201 (2006)

4. Linares, J.J., Rocha, T.A., Zignani, S., Paganin, V.A., Gonzalez, E.R.: Int. J. Hydr. Energy 38, 620 (2013)

5. Alberti, G., Casciola, M.: Annu. Rev. Mater. Res. 33, 129 (2003)

6. Matos, B.R., Isidoro, R.A., Santiago, E.I., Linardi, M., Ferlauto, A.S., Tavares, A.C., Fonseca, F.C.: J. Phys. Chem. C 117, 16863 (2013)

7. Santiago, E.I., Isidoro, R.A., Dresch, M.A., Matos, B.R., Linardi, M., Fonseca, F.C.: Electrochim. Acta 54, 4111 (2009)

8. Matos, B.R., Isidoro, R.A., Santiago, E.I., Fonseca, F.C.: J. Power Sources 268, 706 (2014)

9. Dresch, M.A., Matos, B.R., Fonseca, F.C., Santiago, E.I., Carmo, M., Lanfredi, A.J.C., Balog, S.: J. Power Sources 274, 560 (2015)

10. Di Blasi, A., Baglio, V., Stassi, A., D’Urso, C., Antonucci, V., Arico, A.S.: ECS Trans. 3, 1317 (2006)

11. Alberti, G., Caciola, M., Massinelli, L., Bauer, B.: J. Membr. Sci. 185, 76 (2001)

12. Matos, B.R., Andrade, C.A., Santiago, E.I., Muccillo, R., Fonseca, F.C.: Appl. Phys. Lett. 104, 091904 (2014)

13. F. Rouquerol, J. Rouquerol, K. Sing, Academic Press: San Diego, USA, (1999)

14. Loppinet, B., Gebel, G., Williams, C.E.: J. Phys. Chem. B 101, 1884 (1997)

15. Matos, B.R., Santiago, E.I., Rey, J.F.Q., Ferlauto, A.S., Traversa, E., Linardi, M., Fonseca, F.C.: J. Power Sources 196, 1061 (2011)

16. Favvas, E.P., Stefanopoulos, K.L., Vairis, A., Nolan, J.W., Joensen, K.D., Mitropoulos, A.C.: Adsorption 19, 331 (2013) 